\title{
PRÁTICAS PEDAGÓGICAS AUTORAIS NA EDUCAÇÃO PROFISSIONAL TÉCNICA A PARTIR DA GAMIFICAÇÃO
}

\author{
SALVADOR/BA MAIO/2018
}

\author{
Daiane Amancio Mendes - UNEB - daiamancio@hotmail.com \\ Obdália Santana Ferraz Silva - UNEB - bedaferraz@hotmail.com
}

Tipo: Investigação Científica (IC)

Natureza: Descrição de Projeto em Andamento

Categoria: Métodos e Tecnologias

Setor Educacional: EDUCAÇÃO MÉDIA E TECNOLÓGICA

\begin{abstract}
RESUMO
A gamificação pode ser vista como um fenômeno amplo, um conceito, que tem como um dos principais objetivos, dentre tantos outros, acionar mecanismos para a resolução de problemas, ampliação da aprendizagem e estímulo da motivação. Aliada a este conceito, esta pesquisa pretende resgatar a ideia de ensino por competências, aliando-a às técnicas de gamificação para a ampliação de práticas pedagógicas na educação profissional técnica. Como objetivo que norteia esta pesquisa, temse buscado compreender como os professores se apropriam elou podem se apropriar, de modo autoral, de uma plataforma de gamificação para desenvolver suas práticas pedagógicas na educação profissional técnica. Este trabalho justifica-se pela crescente demanda na educação por alternativas que promovam muito mais que aulas motivadas e imersão entre os alunos, mas que potencializem práticas docentes autorais e capazes de conduzir uma aprendizagem autônoma, que estimulem em seus alunos o desejo de saber. Além disso, pretende legitimar a necessidade de se estudar a gamificação como possibilidade de criação de atividades significativas nos variados espaços de aprendizagem, a fim de motivar o aprendizado e engajar alunos na resolução de problemas, para além da instrumentalidade. Entende-se que é preciso estabelecer práticas que autorizem os estudantes a intervirem em sua autoformação. Para isto, o docente precisa de bases teóricas que experimentem a natureza do seu trabalho de maneira crítica e potencialmente transformadora, atuando a partir da "reflexão + ação". Presando nesse processo, emerge nesta pesquisa o estudo de uma plataforma gamificada, concebida com foco na tríade teoria, motivação e técnica e desenvolvida para o ensino presencial e a distância de uma escola técnica, a fim de engajar os estudantes e professores através de uma experiência lúdica mediante a lógica de interação, engajamento e prazer.
\end{abstract}

Palavras-chave: Prática pedagógica; Gamificação; Educação profissional técnica

\section{AGRADECIMENTOS}

AGRADEÇO AO SENAI - ITED, EM ESPECIAL A MARCELLE MINHO, PELO INCENTIVO E APOIO SEM OS QUAIS ESSE TRABALHO NÃO SERIA POSSÍVEL. 


\section{Introdução}

Com o permanente avanço das tecnologias voltadas para a comunicação, os letramentos digitais compreendem a habilidade de localizar, avaliar e analisar informações usando tecnologia digital, tornando o indivíduo um cidadão digital. (DIGITAL LITERACY, 2010 apud SAITO; SOUZA, 2011). Os multiletramentos surgem então a partir de uma leitura mais ampla e complexa do papel dos letramentos digitais no desenvolvimento das habilidades de comunicação do indivíduo a partir de abordagens funcionais, críticas e retóricas. (SELBER, 2014 apud SAITO; SOUZA, 2011) que possibilitam a promoção da criatividade e inovação, do pensamento crítico e da capacidade de resolução de problemas, colaboração, autonomia, flexibilidade e aprendizagem permanente, características que também se fazem presentes na gamificação, termo que sugiu em 2010 com o conceito de uso de elementos de game design em contextos de não jogos Deterding et al. (2013).

Desde então a gamificação tem feito parte de processos nos quais a experiências de jogos/brincadeiras, enquanto componentes essenciais da sociedade e da cultura (HUIZINGA, 2017), são usados como fonte potencial para a formulação de diferentes estratégias, inclusive de aprendizagem. Geralmente, a gamificação é usada com a intenção de criar no usuário experiências lúdicas, motivar os comportamentos desejados e aumentar a alegria, ao se realizar uma determinada atividade. Para Minho e Alves (2016), a gamificação pode atuar como elemento catalisador de mudanças, e permite ao professor condições de promover atividades pautadas na tríade engajamento, ação e prazer (grifo meu). Para as autoras, é possível, a partir dessa tríade, promover a autonomia e o protagonismo do professor, rompendo a lógica da transmissão em sala de aula.

A partir desta perspectiva, a gamificação pode ser vista como um fenômeno amplo, um conceito, que tem como um dos principais objetivos, dentre tantos outros, acionar mecanismos para a resolução de problemas, ampliação da aprendizagem e estímulo da motivação, baseada em teorias psicológicas que utilizam modelos motivacionais, como a teoria do Flow, desenvolvida pelo psicólogo húngaro Mihaly Csikszentmihalyi (2000). Ele criou o conceito psicológico de fluxo, um estado mental altamente focado, que equilibra desafios e habilidades para atingir um estado de concentração ótimo.

Nesse diapasão, o ensino por competências, a partir dos ensinamentos do suíço Phillippe Perrenoud (2010), que já faz parte da estrutura de ensino do locus desta pesquisa, é estudado, aliado às técnicas de gamificação para a ampliação de práticas pedagógicas na educação profissional técnica. Além destas duas categorias teóricas, a 
Pedagogia da Autonomia de Paulo Freire, é resgatada para discutir o estímulo à curiosidade ingênua como pressuposto para o desenvolvimento da curiosidade epistemológica, fazendo com o que o sujeito, autônomo da sua própria aprendizagem, desenvolva atitudes e ações autorais. Esse três eixos norteadores observados na presente pesquisa contribuirão para discutir a relevância da gamificação como elemento desenvolvedor de práticas pedagógicas autorais.

\section{Objetivos}

Coadunando com o pensamento de Giroux (1997), quando diz que a escola precisa de professores com visão de futuro que possam aliar teoria, imaginação e técnica, o objetivo geral que norteia esta pesquisa é compreender como os professores se apropriam e/ou podem se apropriar, de modo autoral, de uma plataforma de gamificação para desenvolver suas práticas pedagógicas na educação profissional técnica

Especificamente, deseja-se com esta pesquisa:

a. Investigar de que maneira os professores compreendem a autoria dentro do processo de gamificação;

b. Problematizar sobre o potencial pedagógico dos elementos presentes na gamificação para contribuir com práticas pedagógicas autônomas e autorais de professores da educação profissional técnica, visando ao ensino e à aprendizagem;

c. Interpretar se e como a gamificação poderá contribuir para a reconfiguração das práticas pedagógicas dos professores dos cursos técnicos do lócus de pesquisa, baseadas no ensino por competências.

Os objetivos listados acima buscam reponder à seguinte questão de pesquisa: Como os professores da educação profissional técnica se apropriam e/ou podem se apropriar, de modo autoral, da gamificação para o desenvolvimento de suas práticas pedagógicas?

\section{Referencial teórico}

Para atender aos objetivos dispostos nesta pesquisa, bem como respoder à questão norteadora, a presente pesquisa foi desenvolida em cinco capítulos compostos pela introdução (capítulo 1), dois capítulos (capítulos 2 e 3) nos quais serão discorridas as categorias teóricas fundamentais, a trilha metodológica (capítulo 4) percorrida para chegar aos resultados, e o último capítulo (capítulo 5) de análise das informações obtidas através da metodologia e os resultados alcançados acerca dos objetivos 
propostos

O capítulo 2, intitulado Entre missões e batalhas: a educação profissional técnica enquanto espaço criativo traz um breve contexto histórico da educação profissional no Brasil e apresenta o papel desempenhado pelo lócus de pesquisa, compondo-se como importante instituição formadora de profissionais técnicos. Aqui também é apresentada a Metodologia que norteia as práticas pedagógicas instituídas nesta escola técnica, fazendo contraponto com o ensino por competências de Perrenoud (2000).

Ainda neste capítulo, são fomentadas discussões sobre práticas pedagógicas como primeira grande categoria teórica desta pesquisa. Esse conceito é discutido, principalmente, a partir dos estudos desenvolvidos por Hetkowski (2004; 2009; 2016) e pelas ideias de Perrenoud (2002) e seu ensino por competências. O conceito de prática reflexiva de Perrenoud é relacionado também com a Pedagogia da Autonomia de Freire (2017), a partir da qual se faz uma reflexão para o desenvolvimento da autoria, embasado na tese de Silva (2012) e a fim de investigar como ela se manifesta na prática pedagógica, sobretudo na educação profissional técnica.

No capítulo 3, Level Up: Gamificar, é apresentado o conceito de jogo a partir dos teóricos Huizinga (2014) e Caillois (2017) que, apesar de apresentarem ideias diferentes, se coadunam nesta pesquisa. A partir do conceito de jogo, os fundamentos do game design e o conceito de gamificação são chancelados pelos escritos de Salem e Zimmerman (2012), além da pesquisa de Cayres (2015), a fim de fornecer aporte teórico para compreender o processo de desenvolvimento plataforma de gamificação que compõe o objeto desta pesquisa. $O$ conceito de gamificação nesta pesquisa também é alicerçado nos estudos de Deterding (2011) e da tríade da gamificação: engajamento, ação e prazer, apresentada por Minho e Alves (2016). Após a construção dessa teia conceitual, no final do capítulo, busca-se fazer uma conexão entre gamificação e práticas pedagógicas autorais, respaldada nos teóricos já citados aqui.

O quarto capítulo apresenta a etnometodologia fundamentada nos estudos de Coulon (2017) como o caminho metodológico pretendido em busca dos objetivos apresentados nesta pesquisa, a fim de compreender como os professores dão sentido às suas práticas em educação. Nesse capítulo também são apresentados os instrumentos de pesquisa, o Senai DR BA enquanto lócus e os sujeitos convidados a participar. A forma como serão analisados os dados e os resultados obtidos são apresentados ao final deste capítulo.

Capítulo 5 tem como pretensão trazer algumas respostas às indagações construídas ao 
longo desta pesquisa e fomentar outras perguntas, que podem ser apenas o start para outros jogos que virão, "porque o novo brota sem parar." (MORIN, 2011, p. 29).

\section{Procedimentos metodológicos}

Esta pesquisa tem o intuito de destacar essa característica de espaço criativo e libertador que a educação possui e busca compreender e explicar fenômenos e processos com o rigor que um pesquisa acadêmica exige. Todavia em muitos momentos surgem questionamentos acerca dos meios, dos métodos, das regras e das normas. Para me fazer entender, lanço mão das palavras de Anísio Teixeira que diz:

\footnotetext{
Como a medicina, a educação é uma arte. $E$ arte é algo de muito mais complexo e de muito mais completo que uma ciência. Convém, portanto, deixar quanto possível claro de que modo as artes se podem fazer científicas. Arte consiste em modos de fazer. Modos de fazer implicam no conhecimento da matéria com que se está lidando, em métodos de operar com ela e em um estilo pessoal de exercer a atividade artística. (TEIXEIRA, 1997, p. 44)
}

Sabendo da necessidade epistemológica de clarear a compreensão acerca desta pesquisa, entende-se que a abordagem que melhor indicará que caminhos seguir é a abordagem etnometodológica, por compreender-se que este é o método que melhor adere à compreensão do objeto em questão. A etnometodologia, como bem explica Amado, permite-nos conhecer o interior da caixa preta da aula, esse lugar onde alunos e professores se organizam, falam, leem, jogam em certos tempos e lugares, mas não em outros. (AMADO, 2014). Assim, buscando conhecer como se constituem as práticas pedagógicas na educação profissional técnica, a etnometodologia me ajudará a "analisar os métodos ou os procedimentos que os indivíduos utilizam para concretizar as diferentes ações que realizam na sua vida cotidiana." (COULON, 2017, p. 21)

Diante do exposto e levando em conta que à etnometodologia interessa estudar de que forma raciocinam os sujeitos sobre determinado tema, seu objetivo é compreender de que forma os atores sociais realizam uma apreensão comum, partilhada e subjetiva do mundo em que vivem (AMADO, 2014, 89), a partir daí, há que se investigar como os sujeitos desta pesquisa, a saber, os professores, exercem suas práticas pedagógicas em seu cotidiano escolar, vivenciando sua rotina e desempenhando seus papéis de educadores na educação profissional técnica. Além disso, a etnomedologia, ancorada no interacionismo simbólico, ajudará a compreender como os professores se apropriam e/ou podem se apropriar, de modo autoral, de uma plataforma de gamificação para desenvolver suas práticas pedagógicas.

Para tal, é necessário um imbricamento sem o qual a pesquisa não se dá, além do desejo, a interação entre o pesquisador e o pesquisado. Assim como Silva (2006, p. 98), 
ao falar que para a realização de sua pesquisa "fez-se necessário, numa postura etnográfica, apreender o ponto de vista do outro, partilhar a sua realidade, ir a campo, mas fazendo dele o material indispensável para que o discurso sobre o outro tenha sentido", assume-se também, aqui, esse compromisso de fazer desse campo, um espaço de convivência e aprendizado, campo fértil onde nascerão os frutos que alimentarão essa pesquisa.

É partindo dessa questão norteadora que pretende-se entender como uma plataforma digital de gamificação é utilizada enquanto espaço de ensinagem e de que forma se dá o acesso a esse espaço, um ambiente virtual criado, estrategicamente, para professores e alunos ampliarem a experiência e, por que não, o tempo de aprendizagem, extrapolando o espaço físico da sala de aula. Entender como esses sujeitos acessam esse espaço relativamente novo e como se dá este movimento é de fundamental importância para esta pesquisa.

Buscarão-se respostas a essa questão (ainda que sabendo que delas poderão surgir outras perguntas), a partir de uma pesquisa de campo realizada em um período de 4 (quatro) meses, quando o campo será vivenciado de forma mais próxima dos sujeitos, a fim de observar como os processos se constituem em torno do objeto em questão, a saber, suas práticas pedagógicas aliadas à gamificação.

Ao estudar sobre a etnometodologia enquanto método de pesquisa, é preciso considerar o caráter subjetivo da pesquisa e dos sujeitos. Por conta isso, é importante trazer a ideia de que a etnometodologia tem como objetivo "analisar os métodos ou procedimentos que os indivíduos utilizam para concretizar as diferentes ações que realizam na sua vida cotidiana" (COULON, 2017, p. 21). Transpondo esse conceito para uma pesquisa em educação, fica clara a aderência deste método no que tange o estudo da prática pedagógica, olhando o professor quando realiza suas atividades no dia a dia da sua profissão, levando em conta também toda sua completude e subjetividade. A etnometodologia nos leva a observar com atenção as práticas do sujeito, mesmo aquelas às quais chamamos de senso comum, com atenção, pois é nessas ações que é possível compreender e interpretar o comportamento dos indivíduos ou objetos pesquisados. Para Coulon, "a questão é saber como os atores produzem os seus mundos, quais as regras que ordenam esses mundos e seus julgamentos” (2017, p. 25).

Essa conceituação indica que caminho seguir ao realizar uma pesquisa sobre prática pedagógica, na qual a subjetividade importa e muito aos resultados da pesquisa, uma vez que as decisões tomadas pelos indivíduos não só influenciam no resultado da pesquisa, como constituem a própria pesquisa, pois é na ação, na prática docente que o 
professor manifesta seu pensamento, seu desejo, sua visão de mundo e seu conhecimento, enquanto atores sociais.

Esses atores produzem fatos sociais que, como ensina Coulon (2017, p. 27), "não é objeto estável, é o produto da atividade contínua dos homens, que colocam em ação o saber-fazer, os procedimentos, as regras de conduta, isto é, uma metodologia do senso comum que dá sentidos a essas atividades [...]". Por isso buscou-se para esta pesquisa sujeitos que conhecessem tivessem contato com o objeto de forma a utilizá-los sem obrigatoriedade, mas de maneira voluntária, a fim de que pudéssemos apreender melhor as ações realizadas por eles no dia a dia de sua prática.

Nesse diapasão, a habilitação como sujeitos para esta pesquisa se deu sob dois aspectos: o interesse da equipe desenvolvedora da plataforma em trabalhar com o curso em que esses professores atuam, pois a escola técnica em questão desenvolve hoje cursos nas modalidades presencial e a distância, nos níveis técnico, qualificação e cursos rápidos; e também como desejo do professor de fazer uso da plataforma nas suas disciplinas. Este segundo aspecto, decerto, é mais relevante e indispensável para que a integração aconteça.

Em consonância, foram convidados três professores da escola técnica, lócus desta pesquisa. Esses três profissionais foram selecionados por conta da sua participação na plataforma de gamificação de forma constante e interessada, o que permitiu que, inclusive, contribuíssem com ideias para aprimoramento da estratégia. É preciso salientar que, desde o projeto piloto, a plataforma em questão vem sofrendo mudanças e aperfeiçoamentos para aprimoramento e também para atender às demandas que surgiram ao longo do processo. Apesar de fazer uso de mecânicas de jogo programáveis, não há interesse em criar um ambiente estático e rígido. Uma equipe multidisciplinar composta por programadores, game designers, designers e pedagogos têm trabalhado de forma conjunta e ouvido o que dizem os alunos e professores que experimentaram a plataforma, até então.

\section{Considerações finais}

Para Coulon (2017), o contexto na pesquisa social não é um quadro passivo, ele é interpretado e tanto a "ação quanto o próprio contexto em que a ação ocorre podem sofrer reinterpretações ulteriores: as definições da situação não são postas de modo definitivo, então, pelo contrário, constantemente abertas. Nesse setido, na qualidade de pesquisa em andamento, ainda não é possível trazer resultados concretos neste texto, apesar de a própria revisã de literatura já sinalizar os avanços feitos em torno das 
relações construídas a partir das categorias teóricas que aliam prática pedagógica, gamificação e educação profissional.

\section{Referências}

AMADO, João. Manual de investigação qualitativa em educação. 2 ed. Coimbra: Imprensa da Universidade de Coimbra, 2014.

CAILLOIS, Roger. Os jogos e os homens: a máscara e a vertigem. Petrópolis, RJ: Vozes, 2017.

CAYRES, Victor de M. Dramaturgia da expansão: Análise da estrutura dramatúrgica de World of Warcraft. 281 f. (2015) Tese (Doutorado em Artes Cênicas). Universidade Federal da Bahia, Salvador, 2015.

COULON, Alain. Etnometodologia e educação. São Paulo: Cortez, 2017.

CSIKSZENTMIHALYI, Mihaly. Fluir. Lisboa: Relógio D’água, 2002.

DETERDING, Sebastian. Et al. Gamification: toward a definition. CHI 2011, May 7-12, 2011, Vancouver, BC, Canada. Disponível em: $<$ http://gamification-research.org/wp-content/uploads/2011/04/02-Deterding-KhaledNacke-Dixon.pdf>. Acesso em 05 maio 2018.

FREIRE, Paulo. Pedagogia da Autonomia. Rio de Janeiro, São Paulo: Paz e Terra, 2017.

GIROUX, Henry. Os professores como intelectuais. Rumo a uma pedagogia crítica da aprendizagem. Trad. Daniel Bueno. Porto alegre: Artes Médicas,1997.

HETKOWSKI, Tânia Maria. Políticas públicas: Tecnologias da Informação e Comunicação e Novas Práticas Pedagógicas. 214f. (2004) Tese (Doutorado em Educação). Salvador: Universidade Federal da Bahia, 2004.

HETKOWSKI, Tânia Maria. In: PRETTO, Nelson. Pareceres emitidos. Parecer de Nelson Pretto - Faculdade de Educação da UFBA - para a dissertação O Computador na Escola: entre o medo e o Encantamento, de TÂNIA MARIA HETKOWSKI. Salvador, 1997. Disponível em: <https://www2.ufba.br/ pretto/textos/tania.htm>. Acesso em: 05 maio 2018. 
HUIZINGA, Johan. Homo ludens: o jogo como elemento da cultura. São Paulo: Perspectiva, 2017.

MORIN, Edgar. Os sete saberes necessários à educação do futuro. São Paulo: Cortez; Brasília: UNESCO, 2013.

MINHO, Marcelle Rose da S.; ALVES, Lynn. Jogar, experimentar e criar: relatos de experiências formativas gamificadas para professores da educação profissional. Anais. XV SBGames, São Paulo, 2016.

PERRENOUD, Phillipe. A prática reflexiva do ofício de professor. Profissionalização da razão pedagógica. Porto Alegre: Artmed, 2002.

PERRENOUD, Phillipe. 10 novas competências para ensinar. Porto alegre: Artmed, 2000 .

SAITO, Fabiano Santos; RIBEIRO, Patrícia Nora de S. R. (Multi)letramento(s) digital(is) e teoria do posicionamento: análise das práticas discursivas de professoras que se relacionaram com as tecnologias da informação e comunicação no ensino público. RBLA, Belo Horizonte, v. 13, n. 1, p. 37-65, 2013. Disponível em: <http://www.scielo.br/pdf/rbla/v13n1/aop1812.pdf>. Acesso em 05 maio 2018.

SALEM, Katie; ZIMMERMAN, Eric. Regras do jogo: Fundamnetos do design de jogos. Volume 1. São Paulo: Blucher, 2012.

. Regras do jogo: Fundamentos do design de jogos. Volume 2. São Paulo: Blucher, 2012.

Regras do jogo: Fundamentos do design de jogos. Volume 3. São Paulo: Blucher, 2012.

Regras do jogo: Fundamentos do design de jogos. Volume 4. São Paulo: Blucher, 2012.

TEIXEIRA, Anísio. Educação e o mundo moderno. 2a ed. São Paulo: Cia. Editora Nacional, 1977. 